\title{
Involvement of polyunsaturated fatty acids in the control of energy storage and expenditure ${ }^{\mathrm{h}}$
}

\author{
Didier F. Pisani ${ }^{1,3, *}$ and Gérard Ailhaud ${ }^{2}$ \\ ${ }^{1}$ Université Côte d'Azur, CNRS, LP2M, Nice, France \\ 2 Université Côte d'Azur, CNRS, Inserm, IBV, Nice, France \\ ${ }^{3}$ Laboratoire de physiomédecine moléculaire, CNRS UMR7370, Tour Pasteur, faculté de médecine, 28, avenue de Valombrose, 06107 \\ Nice cedex 2, France
}

Received 16 May 2019 - Accepted 22 July 2019

\begin{abstract}
Within heterotrophic organisms, fat, sugar and protein are required to bring energy. In humans, energy homeostasis (i.e. the balance between energy intake and energy expenditure) is tightly regulated. Obesity, characterized by an excess of white fat mass, is a consequence of dysregulation of this balance in which decreased energy expenditure plays an important role. Among dietary components, fat represents approximately $30 \%$ of daily intake. Recent studies have shown that, besides its caloric input, fatty acid composition of fat represents an important qualitative issue. The impact of $\omega 6$ and $\omega 3$ polyunsaturated fatty acids on weight gain and development has been extensively studied. Interestingly, the role played by these polyunsaturated fatty acids in energy expenditure has been also characterized and will be discussed in relation to the various organs involved, in particular brown adipose tissue.
\end{abstract}

Keywords: thermogenesis / fever / shivering / PUFA / oxylipins

Résumé - Implication des acides gras polyinsaturés dans le contrôle du stockage et de la dépense énergétique. Au sein des organismes hétérotrophes, les lipides, les sucres et les protéines sont nécessaires à l'apport d'énergie. Chez l'Homme, l'homéostasie énergétique (c'est-à-dire l'équilibre entre l'apport et la dépense d'énergie) est finement régulée. L'obésité, caractérisée par un excès de tissu adipeux blanc, est une conséquence de la dérégulation de cet équilibre dans laquelle une diminution de la dépense énergétique joue un rôle important. Parmi les composants alimentaires, les lipides représentent environ 30 \% de l'apport quotidien. Des études récentes ont montré que, outre son apport calorique, la composition qualitative en acides gras des lipides alimentaires représente un problème important. En ce sens, l'impact des acides gras polyinsaturés $\omega 6$ et $\omega 3$ sur la prise de poids et le développement a fait l'objet de nombreuses études. De plus, il est intéressant de noter que le rôle joué par ces acides gras polyinsaturés dans les dépenses énergétiques a également été caractérisé et sera discuté en relation avec les différents organes impliqués, en particulier le tissu adipeux brun.

Mots clés : thermogénèse / fièvre / frisson / AGPI / oxylipines

\section{Obesity, adipose tissue and nutrition}

Obesity results from an imbalance between energy input and expenditure. This energy homeostasis is maintained by the activity of metabolic tissues, including white and brown adipose tissue. As adipose tissue is the main peripheral target organ handling fatty acids, any change in lipid intake involves

\footnotetext{
Contribution to the Topical Issue "Lipids and health / Lipides et santé"

*Correspondence: didier .pisani@univ-cotedazur.fr
}

modifications in its development and functions. Importantly, major dietary quantitative and qualitative changes have taken place in the last decades in the Western industrialized world, particularly the overconsumption of $\omega 6$ polyunsaturated fatty acids (PUFAs) and the underconsumption of $\omega 3$ PUFAs by both humans and domesticated animals, which have been associated to an increase in white fat mass leading to obesity. Over the last years, in addition to the well-known relationship between PUFAs and energy storage, new data have emerged linking PUFA to the different mechanisms of energy expenditure.

In this review, we listed the various effects of $\omega 6$ and $\omega 3$ PUFA and long-chain PUFAs to explain that inadequate intake 


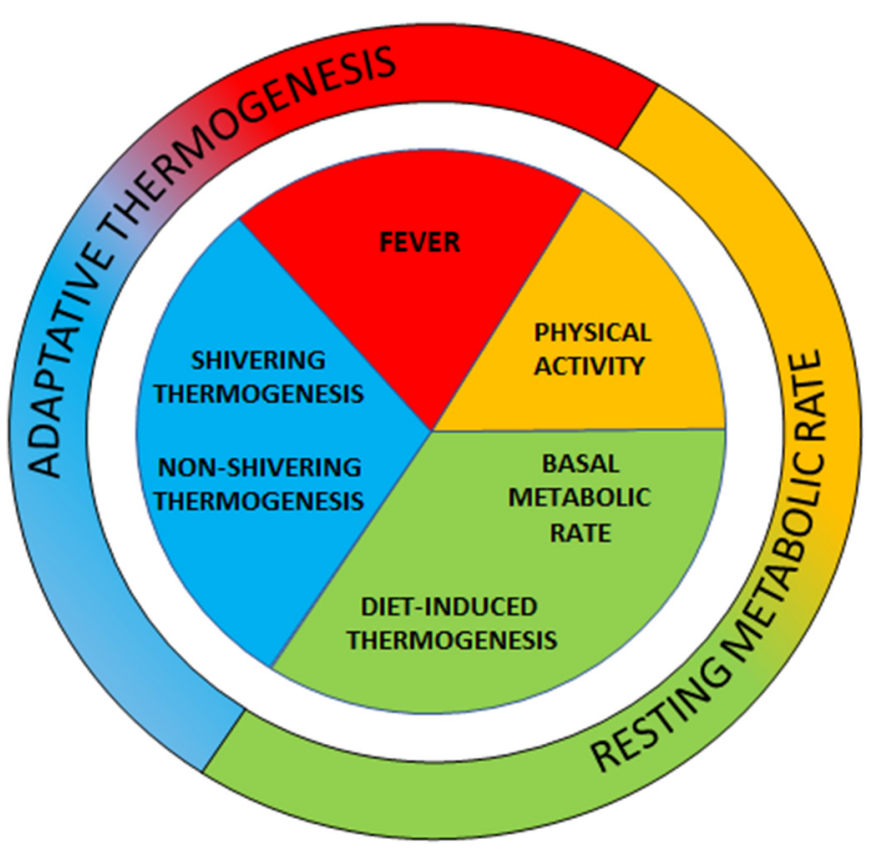

Fig. 1. The different ways of energy expenditure.

of PUFA contributes to energy homeostasis disequilibrium and may represent a risk factor to the occurrence of obesity and metabolic disorders.

\section{Energy expenditure and thermogenesis}

Energy expenditure involves resting and adaptative energy expenditure (Fig. 1). Resting energy expenditure or resting metabolic rate includes physical activity (excluding exercise), diet-induced thermogenesis and all energy expenses required to sustain life functions (named basal metabolic rate and corresponding to breathing, blood circulation, brain and nerve functions). Adaptative energy expenditure is known as a response to specific situations, such as fever with shivering in response to infection and non-shivering thermogenesis in response to cold. Both processes can be modulated/affected by exogenous stimuli which include dietary fatty acids (Himms-Hagen, 2001).

\subsection{Non-shivering thermogenesis}

Non-shivering thermogenesis is activated in response to a cold environment and corresponds to an increase in metabolic heat production above basal metabolism rate (Cannon and Nedergaard, 2004). Distinct from shivering thermogenesis, it is not exclusively associated with muscle activity. It occurs mainly through metabolism of brown fat and less to that of skeletal muscle, liver, brain, and white fat (Cannon and Nedergaard, 2004; Ouellet et al., 2012).

In contrast to white adipose tissue (WAT) involved in energy storage and release, brown adipose tissue (BAT) is endowed with this thermogenic activity to regulate body temperature by dissipating energy. This process is due to the unique occurrence of the Uncoupling protein 1 (UCP1) localized in BAT mitochondria and is both activated and induced in response to cold via $\beta$-adrenergic stimulation
(Cannon and Nedergaard, 2004). The energy-dissipating properties of UCP1 lead to an increased oxidation of fatty acids and carbohydrates and are important for body weight regulation (Blondin et al., 2017). BAT displays various anatomic localizations in humans where the interscapular localization found only in newborns is replaced by cervical and thoracic localization in adults (Zhang and Hao, 2018). In other mammals, the interscapular localization of BAT is maintained throughout adult life in addition to other sites, but its mass and activity decreases with aging (Graja and Schulz, 2015).

Importantly, an additional population of UCP1-positive adipocytes is present in WAT and is termed brite for "brown in white" or beige adipocytes (Barbatelli et al., 2010). These brown-like adipocytes appear in response to cold exposure or to high-fat diets. These cells which stem from progenitors or by direct conversion of mature white adipocytes have been recently found in adult humans (Rosenwald and Wolfrum, 2014). Induction of brown and brite adipocyte activity appears as a novel strategy to combat obesity by enhancing body energy expenditure, i.e. by increasing oxidation of fatty acids within these cells and therefore limiting fat storage in peripheral tissues.

\subsection{Diet-induced thermogenesis}

In addition to the well-known function of BAT in cold acclimation, several other functions of this tissue have been described. The most intriguing response is its post-prandial activation in response to various diets, i.e. diet-induced thermogenesis which takes place concomitantly to the insulin peak which favors energy storage as triglycerides and glycogen (Hibi et al., 2016).

\subsection{Physical activity}

"Physical activity" includes occupational, sports, conditioning, household, or other activities whereas "Exercise" is a subset of planned and structured physical activity. Importantly, physical activity is mainly performed by rapid skeletal muscles known as glycolytic and thus uses preferentially carbohydrates. Thus, it is likely that the fat composition of diet should have lower impact, if any, on this kind of energy expenditure (Westerterp et al., 1996).

\subsection{Shivering thermogenesis}

Exposure to cold induces the activation of involuntary muscle contractions leading to shivering thermogenesis. Skeletal muscles are thus involved in cold resistance and are the main contributor of heat in adult humans compared to other mammals in which BAT thermogenesis prevails (Blondin et al., 2017). In humans, both types of thermogenesis seem more exclusive than additive as shivering activity is inversely correlated to the occurrence of BAT (Ouellet et al., 2012). Shivering thermogenesis uses a variety of metabolic fuels, as oxidation of carbohydrates, lipids and proteins. When one fuel source is depleted or reduced, the others compensate in order to maintain shivering intensity and core temperature (Weber and Haman, 2005). 


\subsection{Fever}

Fever, or pyrexia, is an evolutionarily conserved host thermogenic response to microbial infection. It is defined as an elevated core temperature and is a reflect of an enhanced metabolism characterized by an increase in energy expenditure. Fever is mediated by pyrogenic mediators, such as cytokines (interleukin-1 and -6, IL-1 and IL-6) (Kozak et al., 1998), adipokines (leptin) (Luheshi et al., 1999) or eicosanoids derived from polyunsaturated fatty acids (prostaglandin E2, PGE2) (Engblom et al., 2003) which trigger thermogenic recruitment of peripheral tissues (Evans et al., 2015). This response is counteracted by anti-pyrogenic agents (corticoids, arginin-vasopressin and IL-1 receptor antagonist, IL-1RA) which prevent an harmful increased body temperature (Tatro, 2000). In this respect, the involvement of BAT in fever remains disputed as, on one hand, inflammatory signals allow secretion of norepinephrine by central nervous system, which is considered as a major activator of BAT but, on the other hand, BAT seems excluded from the process which triggers fever in response to endotoxemia (Riley et al., 2016).

\section{Energy expenditure in response to PUFAs}

Polyunsaturated fatty acids (PUFAs) are defined as a class of fatty acids displaying two or more double bonds. The two major PUFAs are $\omega 6$ linoleic acid (LA, 18:2n-6), the precursor of dihomo- $\gamma$-linolenic acid (DGLA, 20:3n-6) and arachidonic acid (ARA, 20:4n-6), and $\omega 3 \alpha$-linolenic acid (LNA, 18:3n-3), the precursor of $\omega 3$ eicosapentaenoic (EPA, 20:5n-3) and docosahexaenoic (DHA, 22:6n-3) acids. These PUFAs (LA and LNA) and long-chain PUFAs (LC-PUFAs) (ARA, DGLA, EPA and DHA) trigger a variety of biological responses and are required for normal development.

In animals, PUFAs are considered as essentials for health owing to their low efficiency (for DHA and to a lower extent for ARA and EPA) or to their inability (for LA, LNA) to synthesize them. Indeed, animals lack the $\Delta$-12-and $\Delta$-15-desaturases able to introduce double bonds in $\mathrm{C} 18$ long chain fatty acids. LA can be found at high proportions in most consumed oils (sunflower [75\%], safflower [79\%], evening primrose seed [72\%], corn [57\%], peanut [31\%] and brassica [19\%]). ALA is found in linseed (also named flaxseed) and various oils (linseed [50\%], black currant seed [14\%] and for a lower extent in rapeseed [9\%]). EPA and DHA are present mainly in algae and marine bacteria. PUFAs can be also ingested via meat and fish, due to their high consumption of $\omega 6$ and $\omega 3$ PUFAs. Indeed, ARA is found in high amounts in bovine, porcine, ovine and poultry meats as well as in fish flesh, milk and eggs. Intake of EPA and DHA is less important than ARA intake as only found in wild fishes 'salmon, mackerel and tuna). In order to increase EPA and DHA intake in humans, two strategies are developed using dietary supplements (fish oil, seed oil) or supplementing livestock diet (especially cow, pork, chicken and salmon) with $\omega 3$ enriched food like linseed and algae (Weill et al., 2002; Bourre, 2005).

\subsection{The critical $\omega 6$ and $\omega 3$ PUFAs intakes in obesity and chronic diseases}

Both $\omega 6$ and $\omega 3$ PUFAs are transported into the bloodstream and are incorporated as phospholipids in plasma membranes or as triglycerides within adipocyte droplets. PUFAs are released by lipases and then oxidized. $\omega 6$ and $\omega 3$ PUFAs are known to compete at different enzymatic steps that modulate the availability of their respective metabolic products (Fig. 2). LA and LNA are substrates of the same $\Delta$-5- and $\Delta$-6-desaturases and elongases to generate the LCPUFAs ARA, DGLA, EPA and DHA. They are also competitors as substrates for the synthesis of oxygenated derivatives or for $\beta$-oxidation, $\omega 3$ PUFAs being more rapidly oxidized compared to $\omega 6$ PUFAs and to mono-unsaturated fatty acids (Cunnane, 2003). Due to these different competition levels, the intake amount of $\omega 6$ and $\omega 3$ PUFAs is crucial to determine the kind of mediators available and the downstream biological processes which will be ultimately induced (Bibus and Lands, 2015). For a long-time, dietary recommendations were mainly addressed to pregnant women and based on an optimal LA/LNA ratio for a healthy development of fetuses and children (Simopoulos and DiNicolantonio, 2016).

Numerous studies carried out in rodent models and in human cohorts have shown a tight link between increased $\omega 6$ PUFA intake, generally associated with a high LA/LNA ratio, and enhanced fat mass. In mice, high fat diet rich in $\omega 6$ PUFA favored fat accumulation, in contrast to $\omega 3$ PUFAenriched diet which lowered this accumulation (Javadi et al., 2004). Similar results have been obtained in rats, where $\omega 6$ PUFA-enriched diet enhanced fat pad weight compared to saturated FA or $\omega 3$ PUFA-enriched diets (Okuno et al., 1997). Interestingly, transgenerational studies developed in rodents have shown that perinatal exposition to high fat diets with high levels of $\omega 6$ PUFA induced a progressive accumulation of body fat across generations (Massiera et al., 2010). In the same way, increasing the LA/LNA ratio from 2 to 30 during the preweaning period of guinea pigs led to an increased fat mass at the middle age (Pouteau et al., 2010; Castaneda-Gutierrez et al., 2011). In humans, a high LA/LNA PUFA ratio in maternal milk, independently from mother weight, is positively associated with the adiposity of infants at 6 months, 3 and 4 years of age (Donahue et al., 2011; Moon et al., 2013; Rudolph et al., 2017). In adults, $\omega 6$ PUFA intake correlates positively with the body mass index (BMI) and the associated metabolic syndrome (Garaulet et al., 2001; Williams et al., 2007; Inoue et al., 2013).

Moreover, in adults both a high intake of $\omega 6 \mathrm{LA}$ and diets associated with a very high LA/LNA PUFA ratios have been associated with the development of several chronic diseases, including cardiovascular, inflammatory and especially overweight/obesity (Ailhaud and Guesnet, 2004; Hibbeln et al., 2006; Okuyama et al., 2007a, b). Accordingly, new dietary recommendations emphasize higher intake of $\omega 3$ PUFAs and lower intake of $\omega 6$ PUFAs to improve human health (Ailhaud et al., 2006; Muhlhausler and Ailhaud, 2013; Simopoulos, 2016; Simopoulos and DiNicolantonio, 2016).

In contrast to $\omega 6$ PUFA excessive intake, it has been reported that diets enriched with $\omega 3$ PUFAs or $\omega 3$ LC-PUFAs 


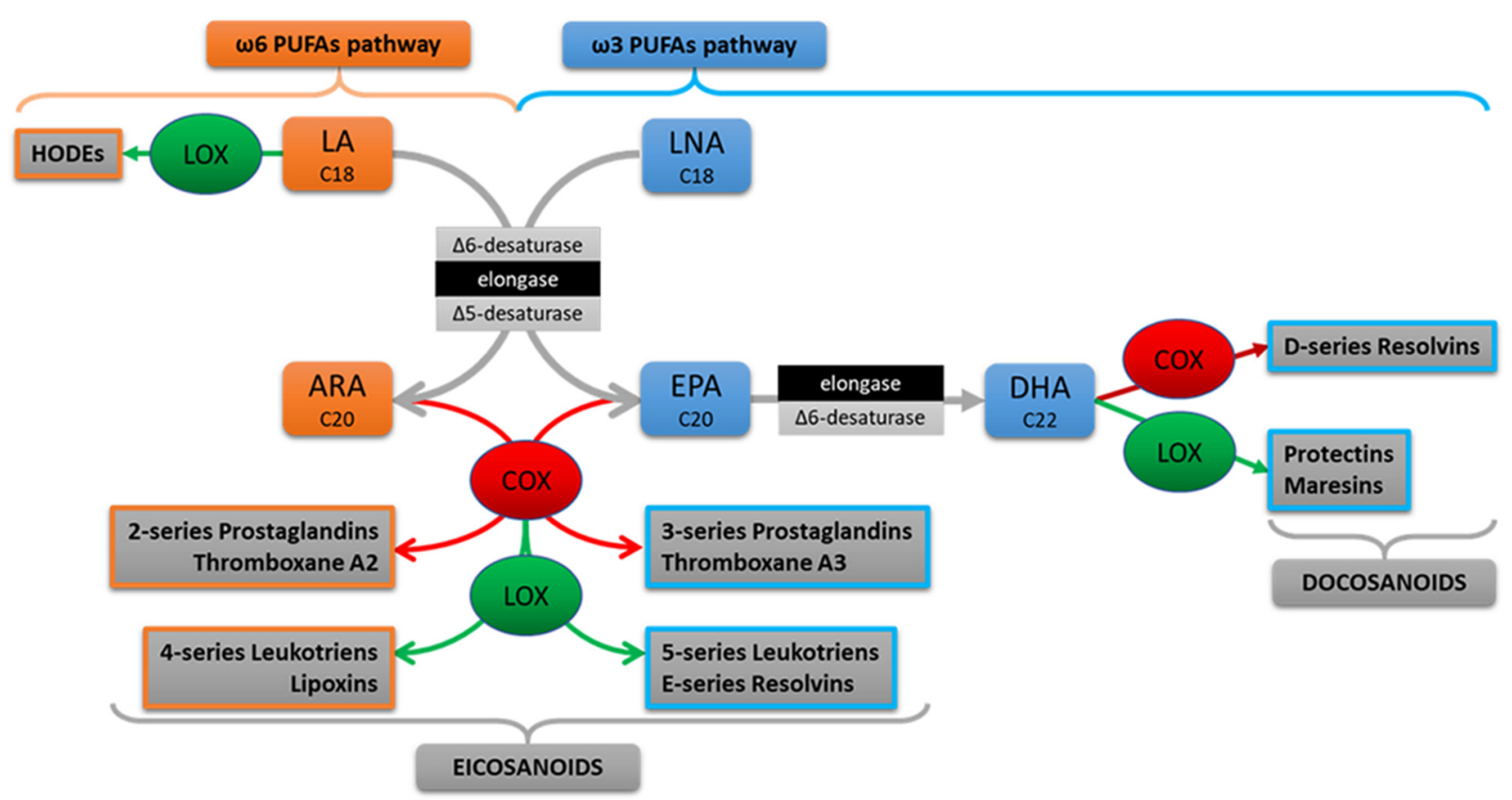

Fig. 2. Major pathways of PUFA metabolization, from dietary fatty acids to major members of the oxylipin family, including the commons enzymatic hubs of metabolization between $\omega 6$ and $\omega 3$ PUFAs. COX: cyclooxygenase; LOX: lipoxygenase; HODEs: hydroxyoctadecadienoic acids; LA: linoleic acid; LNA: alpha-linolenic acid; ARA: arachidonic acid; EPA: eicosapentaenoic acid; DHA: docosahexaenoic acid. The number of carbon atoms is indicated.

lead to beneficial effects and contribute to improve of human health. Cohort analyses have shown normalization of inflammation, lowering plasma triglycerides and amelioration of the cardiovascular metabolic status (Duda et al., 2009; Innes and Calder, 2018). In rodents, inclusion of LNA in LA- rich high fat diet prevents the enhancement of fat mass (Massiera et al., 2003). A similar favorable effect is observed for body weight in humans whereas inclusion of EPA and DHA leads to lower cardiovascular disease risk and ameliorates metabolic markers (Simopoulos and DiNicolantonio, 2016; Jayarathne et al., 2017).

\subsection{Active metabolites of PUFAs}

Most biological functions are not attributed directly to PUFAs but rather mediated through some of their oxygenated metabolites. These metabolites, termed oxylipins, are synthesized in a highly regulated manner, mainly by cyclooxygenases (COX-1 and COX-2) and lipoxygenases (3-, 5-, 12- and 15LOX) activities (Fig. 2), displaying both a high biological potency and a short half-life (Funk, 2001, Perez-Chacon et al., 2009). After synthesis, these oxygenated derivatives can:

- undergo new enzymatic modifications;

- activate soluble intracellular receptors;

- diffuse out of the cell through the plasma membrane and signal through membrane receptors in a paracrine or autocrine manner;

- stored as esterified fatty acids included within cell membranes.

In turn, these esterified oxylipins can be hydrolyzed from the membrane under specific stimuli to actively participate into various biological responses (Hammond and O'Donnell, 2012).

Synthesis of oxylipins takes place from developmental stages to adult life. In mammals, oxylipins can be divided into two main categories (Fig. 2), the eicosanoids (synthesized from C20 PUFAs, i.e. ARA, EPA and dihomo- $\gamma$-linolenic acid, DGLA) and the docosanoids (synthesized from C22 PUFAs, $i$. e. DHA) (Massey and Nicolaou, 2013). A third class of metabolites are derived directly from linoleic acid and composed of two members, 9- and 13-HODEs (hydroxyoctadecadienoic acid). Oxylipins, which differ by their length and double bond configuration, are synthesized by several alternative and consecutive reactions and display crucial signaling functions. Among ARA metabolites, prostacyclin (PGI2) has been shown in mice to trigger in vitro adipose cell differentiation (Negrel et al., 1989) and in vivo adipose tissue formation (Massiera et al., 2003).

There is a direct link between PUFA dietary intake and synthetized oxylipins in plasma and tissues. In rodents, increasing ARA or LA intake increases $\omega 6$ PUFA-derived oxylipins (Pisani et al., 2014; Pisani et al., 2015; Ghandour et al., 2018), a profile reversed by addition of LNA (Ghandour et al., 2018; Colson et al., 2019). In humans, studies have been mainly focused on $\omega 3$-diet supplementation which leads to an increase of $\omega 3$-derived metabolites; however the oxylipin levels return to almost normal levels when the $\omega 3$-diet supplementation was discontinued (Fischer et al., 2014). Moreover, in a cohort of hyperlipidemic patients, a 3-month diet supplemented in $\omega 3$ PUFAs leads to an increase in $\omega 3$ derived metabolites in red blood cell membranes, almost attaining the proportion observed in healthy patients (Harris 
and Von Schacky, 2004; Schmocker et al., 2018). This increase in oxylipin synthesis can be acute, as demonstrated recently where both EPA- and DHA-enriched meals induce within 4 hours a potent increase of $\omega 3$-derived metabolites in plasma (McManus et al., 2016).

\subsection{PUFA supplementation and energy expenditure}

Few data are available regarding the impact of PUFA and LC-PUFA supplementation on the resting metabolic rate which should be poorly modulated as it is critical for life. In contrast, several studies have analyzed the impact of the different PUFA classes on adaptive thermogenesis and physical activities.

\subsubsection{PUFAs and non-shivering thermogenesis}

Some studies have been carried out regarding the involvement of PUFA and their metabolites in the activation of BAT and in the conversion of white into brite adipocytes, both in vivo and in vitro (Kuda et al., 2018). Recently, our group (Pisani et al., 2014; Pisani et al., 2015; Ghandour et al., 2018; Colson et al., 2019) has shown the importance of the $\omega 6$ and $\omega 3$ PUFAs and LC-PUFAs dietary intake on adipose tissue development and function. ARA enriched diets, known to favor white adipose tissue formation, prevent the "browning" process to take place in white adipose tissue depots (Pisani et al., 2014), suggesting a favorable role of $\omega 3$-PUFA supplementation in preventing both processes. Indeed, $\omega 3$ PUFA and LC-PUFAs supplementation has beneficial effect on the thermogenic function of adipocytes. A low dietary LA/ LNA ratio (4 compared to 25) improved the thermogenic response of BAT and WAT under $\beta 3$-adrenergic stimulation (Ghandour et al., 2018). The eicosanoid PGF2 $\alpha$ appears responsible of these effects, the level of which is influenced by the availability of $\omega 6$ and $\omega 3$ PUFAs competing at the level of their metabolization.

Few studies showed a direct relationship between $\omega 3$ PUFAs enriched diet and induction of brown adipocyte thermogenesis (Adkins et al., 2017, Kuda et al., 2018). However, it also has been shown that $\omega 3$ PUFAs favored the formation of the so-called "healthy adipocytes" with high number of mitochondria but not expressing UCP1 (Kuda et al., 2018). Moreover, other studies have shown the beneficial effect of $\omega 3$ PUFA supplementation on glucose metabolism (glucose tolerance, insulin sensitivity) and on BAT activation and/or brite adipocyte formation (Kim and Goto, 2015; Pahlavani et al., 2017). In vivo studies have shown a global increase in thermogenesis in mice fed fish oil $\omega 3$-enriched food, i.e. an increased rectal temperature associated with an increase of brown adipocyte markers in BAT (Kim et al., 2016). Furthermore, mice fed fish oil (enriched with EPA or DHA) diets also display a strong increase in UCP1 expression in inguinal WAT (Kim and Goto, 2015). In this study, was examined the pathway by which $\omega 3$ PUFAs could exert their effect using $\beta$-adreno-receptor blockers. Indeed, 4 hours of fish oil diet are enough to induce UCP1 in BAT and this effect was abolished when the mice received propranolol as a $\beta$-adrenergic receptor blocker (Kim and Goto, 2015). In another study, mice fed control diet supplemented with EPA $(36 \mathrm{~g} / \mathrm{kg}$ for 11 weeks) display an increased expression of UCP1 in BAT whereas no effect is observed in WAT (Pahlavani et al., 2017). Although EPA appears important for BAT activity, it cannot be excluded that others $\omega 3$ PUFAs present in fish oil are important for this activity.

In addition to their role in brown and brite adipocytes differentiation and function, oxylipins are well-known modulator of white adipocyte development and function. For example, prostacyclin (PGI2) synthesized from ARA can promote adipogenesis. Indeed, secreted prostacyclin from preadipocyte binds to its receptor IP in an autocrine/paracrine way and leads to cAMP pathway activation. This enhances the differentiation of preadipocytes via the expression of $\mathrm{C} / \mathrm{EBP} \beta$ and C/EBPS (C/Enhancer Binding Proteins) (Vassaux et al., 1992; Massiera et al., 2003), both of which being critical for the progression of early phase of adipogenesis and the activation of PPARs (peroxisome proliferator-activated receptors) (Brun et al., 1996). In addition to activating plasma membrane receptors, PGI2 can also signal directly through PPARs activation to promote adipogenesis (Forman et al., 1995). This dual signalling is allowed by the localization of the prostacyclin synthase PGIS at the plasma or at the nuclear membrane (Lim and Dey, 2002). The involvement of PGI2 in adipogenesis have been confirmed in vivo in mice invalidated for its receptor IP. Indeed, these mice displayed less body weight and fat mass compared to wild type mice when fed with a LA-rich diet (Massiera et al., 2003). In addition to PGI2, some others ARA metabolites generated through cyclooxygenase activities, as PGD2 and 15d-PGJ2, had been described to stimulate adipogenesis (Forman et al., 1995).

\subsubsection{PUFAs and fever}

Infection and inflammation result in a negative energy balance with an increased thermogenesis (also named fever, pyrexia or febrile state) and decreases food intake. As fever is mediated mainly by leptin, IL-1 $\beta$, IL-6 and PGE2, all factors modulating production/secretion of these mediators should be able to mediate fever.

IL-1 $\beta$ and IL-6 are two pro-inflammatory cytokines released by immune cells and crucial to the regulation/ induction of fever by the brain (Kozak et al., 1998). It is well accepted that $\omega 6$ PUFAs leads to the synthesis of inflammatory eicosanoids (including PGE2) and that $\omega 3$ PUFAs display anti-inflammatory properties, mainly by the production of anti-inflammatory eicosanoids and docosanoids, but also by the modulation of inflammatory cytokine expression (Calder, 2006). Mice feeding diet enriched with fish or rapeseed oil ( $\omega 3$-enriched oils) displayed a decreased IL-1 $\beta$ and/or IL-6 levels in blood (Sadeghi et al., 1999) as well as in brain (Delpech et al., 2015) under endotoxemia conditions. This effect of $\omega 3$ PUFAs is still under debate as it was not already found under healthy conditions (Colson et al., 2019) but mainly under pathological or inflammatory conditions.

PGE2 is an indispensable brain mediator of fever as demonstrated in studies with targeted disruption of genes encoding either PGE2-synthesizing enzymes (Engblom et al., 2003) or PGE2 receptors (Ushikubi et al., 1998), or using pharmaceutic compounds such as aspirin, salicylate, indomethacin or celecoxib (Romanovsky, 2005). In addition, other prostaglandin and non-prostaglandin metabolites 
derived from arachidonic acid have been involved in the central control of fever in response to inflammation (Kozak and Fraifeld, 2004). Due to the tight regulation of oxylipin synthesis in face of the quantity and quality of dietary PUFAs, a direct correlation exists between $\omega 6 / \omega 3$ PUFAs and LCPUFAs ratio and the various pathways involving oxylipins in fever.

Leptin has been characterized in murine models as a fever mediator of body temperature (Luheshi et al., 1999). Little is known about the detailed mechanism linking leptin and pyrexia. Leptin acts at the level of hypothalamus, may be by modulation of IL-1 $\beta$ expression and IL-6 (Pohl et al., 2014), which induces a decrease in heat loss and thus an increase in body temperature (Fischer et al., 2016; Kaiyala et al., 2016). As PUFA intake modulated fat mass development which is directly correlated to leptin secretion (Garaulet et al., 2001; Williams et al., 2007; Inoue et al., 2013), we assume that regulation of fat mass by dietary PUFAs indirectly modulated fever and thus energy expense during inflammation/infection. Interestingly, DHA has been characterized as a determinant of leptin gene expression (Shen et al., 2014), but human studies failed to clearly correlate $\omega 3$ PUFA intake to leptin circulating level in diabetic and healthy populations (Kratz et al., 2002; Stirban et al., 2014).

\subsubsection{PUFAs and muscle function}

Physical activity increases with body weight as body mass to move is increased. Indeed, even if amplitude and velocity are lowered in obese and overweight subjects, the whole strength developed is similar to lean people (Lazzer et al., 2003). Obesity is still associated (as a cause or as a consequence) with a sedentary lifestyle. This behavior, involving as a chronic decrease of physical activity frequency, drives de facto a decrease in energy expenditure associated to limited daily life activities (Carneiro et al., 2016). Therefore, as PUFAs intake has been related to fat mass development, if causality between decreased activities and PUFAs intake exists; it should be rather indirect.

Nevertheless, several studies have described a relationship between dietary PUFAs and muscle mass and function, independent of body weight change (Jeromson et al., 2015; Gammone et al., 2018). Firstly, PUFAs seem to affect muscle anabolism, including muscle growth and regeneration (Tachtsis et al., 2018). Other studies have shown an increased muscle protein synthesis in both young and older subjects undergoing a daily administration of $\omega 3$ PUFAs for eight weeks (Smith and Atherton, 2011). A similar result on muscle mass is obtained after six months of $\omega 3$ PUFAs supplementation in older people with an additional increase in muscle strength (Smith et al., 2015). Secondly, $\omega 3$ PUFA intake ameliorates muscle metabolism and function. In mice submitted to a high fat diet, a four-week daily supplementation with $\omega 3$ PUFAs reversed lipid accretion and increased oxidative metabolism in muscle. Interestingly, in this study, the authors describe an increase in BAT mass which can be relied to the positive effect of $\omega 3$ PUFA intake (Philp et al., 2015).

Overall, even if $\omega 6$ and $\omega 3$ PUFA intakes do not modulate physical activities per se, they have an impact on skeletal muscle capacity and can influence indirectly energy expenditure during exercise.

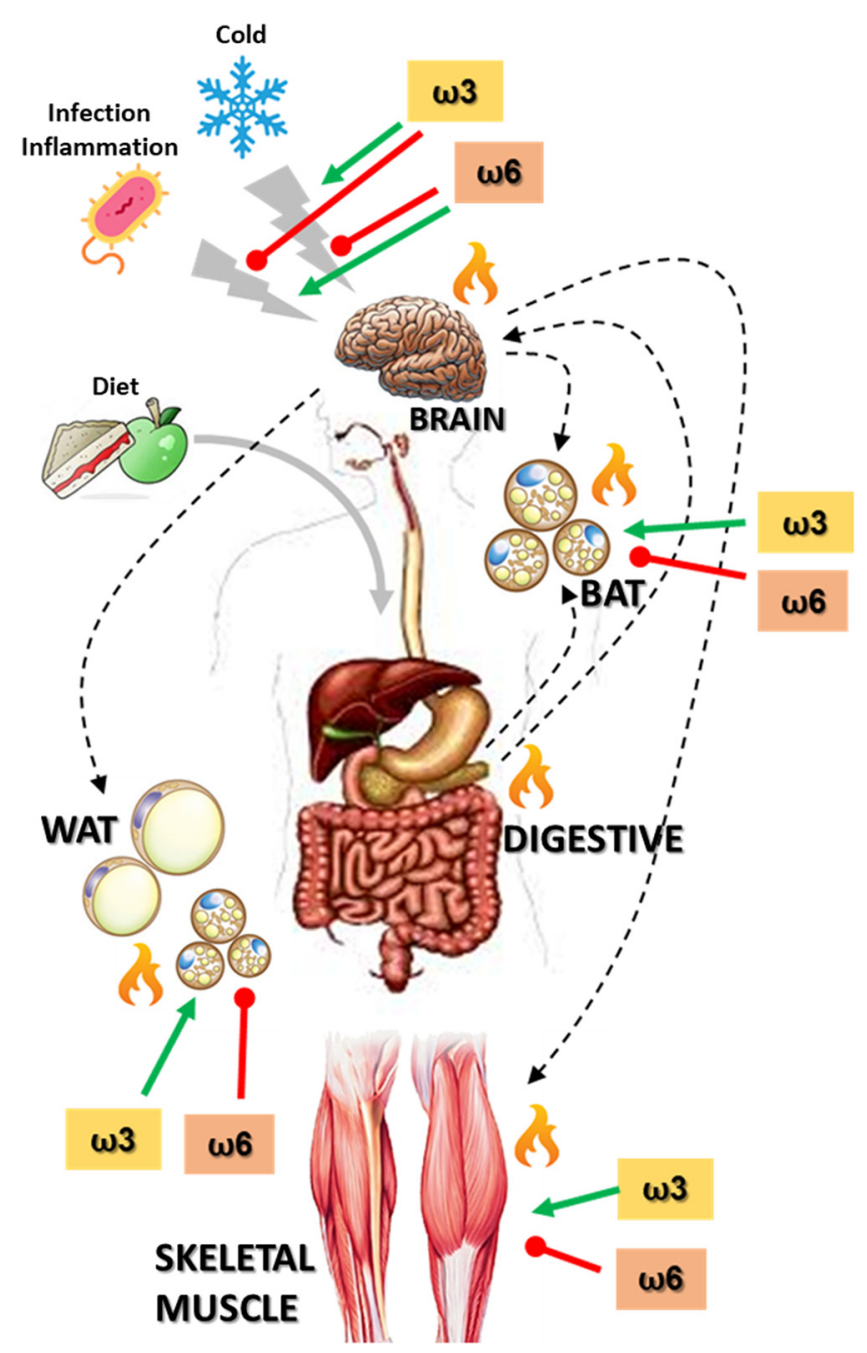

Fig. 3. Major thermogenic tissues, interrelationships and modulation by $\omega 6$ and $\omega 3$ PUFAs and LC-PUFAs. Red rounded-head arrow: negative action. Green arrow: positive action. Black arrow: modulatory pathways between organs. Grey arrow: environmental effectors. Flame: heat production.

\section{Conclusions}

$\omega 6$ and $\omega 3$ PUFAs and LC-PUFAs can be considered as two important actors regulating energy expenditure. Neither exclusive positive nor unfavorable involvement of the different PUFAs is observed, as each of them can promote or inhibit different kinds of energy expenditure (Fig. 3). Nevertheless, excessive dietary intake of $\omega 6$ PUFAs can overall be considered as negative regulators and adequate intake of $\omega 3$ PUFAs as positive counter-regulators of various metabolic events. Indeed, excess of $\omega 6$ PUFAs or insufficient $\omega 3$ PUFAs intake favor fat mass development which can be relied to a decrease in both non-shivering thermogenesis and physical activity due to sedentary lifestyle. Conversely, $\omega 3$ PUFAs supplementation is limiting fat mass increase as well as promoting thermogenesis and physical activity. Of note, as both $\omega 6$ and $\omega 3$ PUFAs are essential and metabolically related to each other (Fig. 2), it is difficult to bring unequivocal and 
direct effect of $\omega 6$ PUFAs distinct from $\omega 3$ PUFAs on the different types of energy expenditure (Fig. 3). Another critical issue of the reported studies has been the use of high $\omega 6$ PUFAs intake and/or various $\omega 3$ PUFAs supplementation which appear widely different from nutritional recommendations. Overall, in 2010, the French Agency for Food, Environmental and Occupational Health \& Safety (ANSES) recommended an intake of $4 \%$ of LA, $1 \%$ of LNA and $250 \mathrm{mg}$ of both EPA and DHA for an adult consuming $2000 \mathrm{kCal} / \mathrm{day}$ (https://www. anses.fr/en/content/fats), this nutritional recommendation appearing adequate to regulate an optimal impact on energy storage and expenditure.

\section{References}

Adkins Y, Belda BJ, Pedersen TL, et al. 2017. Dietary docosahexaenoic acid and trans-10, cis-12-conjugated linoleic acid differentially alter oxylipin profiles in mouse periuterine adipose tissue. Lipids 52(5): 399-413.

Ailhaud G, Guesnet P. 2004. Fatty acid composition of fats is an early determinant of childhood obesity: a short review and an opinion. Obes Rev 5(1): 21-26.

Ailhaud G, Massiera F, Weill P, Legrand P, Alessandri JM, Guesnet P. 2006. Temporal changes in dietary fats: role of n-6 polyunsaturated fatty acids in excessive adipose tissue development and relationship to obesity. Prog Lipid Res 45(3): 203-236.

Barbatelli G, Murano I, Madsen L, et al. 2010. The emergence of cold-induced brown adipocytes in mouse white fat depots is determined predominantly by white to brown adipocyte transdifferentiation. Am J Physiol Endocrinol Metab 298(6): E1244E1253.

Bibus D, Lands B. 2015. Balancing proportions of competing omega3 and omega-6 highly unsaturated fatty acids (HUFA) in tissue lipids. Prostaglandins Leukot Essent Fatty Acids 99: 19-23.

Blondin DP, Tingelstad HC, Noll C, et al. 2017. Dietary fatty acid metabolism of brown adipose tissue in cold-acclimated men. Nat Commun 8: 14146.

Bourre JM. 2005. Where to find omega-3 fatty acids and how feeding animals with diet enriched in omega-3 fatty acids to increase nutritional value of derived products for human: what is actually useful? J Nutr Health Aging 9(4): 232-242.

Brun RP, Tontonoz P, Forman BM, et al. 1996. Differential activation of adipogenesis by multiple PPAR isoforms. Genes Dev 10(8): 974-984.

Calder PC. 2006. Polyunsaturated fatty acids and inflammation. Prostaglandins Leukot Essent Fatty Acids 75(3): 197-202.

Cannon B, Nedergaard J. 2004. Brown adipose tissue: function and physiological significance. Physiol Rev 84(1): 277-359.

Carneiro IP, Elliott SA, Siervo M, et al. 2016. Is obesity associated with altered energy expenditure? Adv Nutr 7(3): 476-487.

Castaneda-Gutierrez E, Pouteau E, Pescia G, Moulin J, Aprikian O, Mace K. 2011. The guinea pig as a model for metabolic programming of adiposity. Am J Clin Nutr 94(6 Suppl.): 1838S-1845S.

Colson C, Ghandour RA, Dufies O, et al. 2019. Diet supplementation in omega 3 polyunsaturated fatty acid favors an anti-inflammatory basal environment in mouse adipose tissue. Nutrients 11(2).

Cunnane SC. 2003. Problems with essential fatty acids: time for a new paradigm? Prog Lipid Res 42(6): 544-568.

Delpech JC, Thomazeau A, Madore C, et al. 2015. Dietary n-3 PUFAs deficiency increases vulnerability to inflammation-induced spatial memory impairment. Neuropsychopharmacology 40(12): 2774 2787.
Donahue SM, Rifas-Shiman SL, Gold DR, Jouni ZE, Gillman MW, Oken E. 2011. Prenatal fatty acid status and child adiposity at age 3 years: results from a US pregnancy cohort. Am J Clin Nutr 93 (4): 780-788.

Duda MK, O'Shea KM, Tintinu A, et al. 2009. Fish oil, but not flaxseed oil, decreases inflammation and prevents pressure overload-induced cardiac dysfunction. Cardiovasc Res 81(2): 319-327.

Engblom D, Saha S, Engstrom L, Westman M, Audoly LP, Jakobsson PJ, Blomqvist A. 2003. Microsomal prostaglandin E synthase-1 is the central switch during immune-induced pyresis. Nat Neurosci 6 (11): 1137-1138.

Evans SS, Repasky EA, Fisher DT. 2015. Fever and the thermal regulation of immunity: the immune system feels the heat. Nat Rev Immunol 15(6): 335-349.

Fischer AW, Hoefig CS, Abreu-Vieira G, et al. 2016. Leptin raises defended body temperature without activating thermogenesis. Cell Rep 14(7): 1621-1631.

Fischer R, Konkel A, Mehling H, et al. 2014. Dietary omega-3 fatty acids modulate the eicosanoid profile in man primarily via the CYP-epoxygenase pathway. J Lipid Res 55(6): 1150-1164.

Forman BM, Tontonoz P, Chen J, Brun RP, Spiegelman BM, Evans RM. 1995. 15-Deoxy-delta 12, 14-prostaglandin J2 is a ligand for the adipocyte determination factor PPAR gamma. Cell 83(5): 803-812.

Funk CD. 2001. Prostaglandins and leukotrienes: advances in eicosanoid biology. Science 294(5548): 1871-1875.

Gammone MA, Riccioni G, Parrinello G, D’Orazio N. 2018. Omega3 polyunsaturated fatty acids: benefits and endpoints in sport. Nutrients 11(1).

Garaulet M, Perez-Llamas F, Perez-Ayala M, et al. 2001. Site-specific differences in the fatty acid composition of abdominal adipose tissue in an obese population from a Mediterranean area: relation with dietary fatty acids, plasma lipid profile, serum insulin, and central obesity. Am J Clin Nutr 74(5): 585-591.

Ghandour RA, Colson C, Giroud M, et al. 2018. Impact of dietary omega 3 polyunsaturated fatty acid supplementation on brown and brite adipocyte function. J Lipid Res.

Graja A, Schulz TJ. 2015. Mechanisms of aging-related impairment of brown adipocyte development and function. Gerontology 61 (3): 211-217.

Hammond VJ, O'Donnell VB. 2012. Esterified eicosanoids: generation, characterization and function. Biochim Biophys Acta 1818(10): 2403-2412.

Harris WS, Von Schacky C. 2004. The Omega-3 index: a new risk factor for death from coronary heart disease? Prev Med 39(1): 212-220.

Hibbeln JR, Nieminen LR, Blasbalg TL, Riggs JA, Lands WE. 2006. Healthy intakes of n-3 and n-6 fatty acids: estimations considering worldwide diversity. Am J Clin Nutr 83(6 Suppl.): 1483S-1493S.

Hibi M, Oishi S, Matsushita M, et al. 2016. Brown adipose tissue is involved in diet-induced thermogenesis and whole-body fat utilization in healthy humans. Int J Obes (Lond) 40(11): 16551661.

Himms-Hagen J. 2001. Does brown adipose tissue (BAT) have a role in the physiology or treatment of human obesity? Rev Endocr Metab Disord 2(4): 395-401.

Innes JK, Calder PC. 2018. The differential effects of eicosapentaenoic acid and docosahexaenoic acid on cardiometabolic risk factors: a systematic review. Int J Mol Sci 19(2).

Inoue K, Kishida K, Hirata A, Funahashi T, Shimomura I. 2013. Low serum eicosapentaenoic acid / arachidonic acid ratio in male subjects with visceral obesity. Nutr Metab (Lond) 10(1): 25. 
Javadi M, Everts H, Hovenier R, et al. 2004. The effect of six different C18 fatty acids on body fat and energy metabolism in mice. $\mathrm{Br} J$ Nutr 92(3): 391-399.

Jayarathne S, Koboziev I, Park OH, Oldewage-Theron W, Shen CL, Moustaid-Moussa N. 2017. Anti-inflammatory and anti-obesity properties of food bioactive components: effects on adipose tissue. Prev Nutr Food Sci 22(4): 251-262.

Jeromson S, Gallagher IJ, Galloway SD, Hamilton DL. 2015. Omega-3 fatty acids and skeletal muscle health. Mar Drugs 13(11): 6977-7004.

Kaiyala KJ, Ogimoto K, Nelson JT, Muta K, Morton GJ. 2016. Physiological role for leptin in the control of thermal conductance. Mol Metab 5(10): 892-902.

Kim J, Okla M, Erickson A, Carr T, Natarajan SK, Chung S. 2016. Eicosapentaenoic acid potentiates brown thermogenesis through FFAR4-dependent up-regulation of miR-30b and miR-378. J Biol Chem 291(39): 20551-20562.

Kim M, Goto T, Yu R, et al. 2015. Fish oil intake induces UCP1 upregulation in brown and white adipose tissue via the sympathetic nervous system. Sci Rep 5: 18013.

Kozak W, Fraifeld V. 2004. Non-prostaglandin eicosanoids in fever and anapyrexia. Front Biosci 9: 3339-3355.

Kozak W, Kluger MJ, Soszynski D, et al. 1998. IL-6 and IL-1 beta in fever. Studies using cytokine-deficient (knockout) mice. Ann N Y Acad Sci 856: 33-47.

Kratz M, von Eckardstein A, Fobker M, et al. 2002. The impact of dietary fat composition on serum leptin concentrations in healthy nonobese men and women. J Clin Endocrinol Metab 87(11): 5008-5014.

Kuda O, Rossmeisl M, Kopecky J. 2018. Omega-3 fatty acids and adipose tissue biology. Mol Aspects Med 64: 147-160.

Lazzer S, Boirie Y, Bitar A, et al. 2003. Assessment of energy expenditure associated with physical activities in free-living obese and nonobese adolescents. Am J Clin Nutr 78(3): 471-479.

Lim H, Dey SK. 2002. A novel pathway of prostacyclin signalinghanging out with nuclear receptors. Endocrinology 143(9): 32073210 .

Luheshi GN, Gardner JD, Rushforth DA, Loudon AS, Rothwell NJ. 1999. Leptin actions on food intake and body temperature are mediated by IL-1. Proc Natl Acad Sci U S A 96(12): 7047-7052.

Massey KA, Nicolaou A. 2013. Lipidomics of oxidized polyunsaturated fatty acids. Free Radic Biol Med 59: 45-55.

Massiera F, Saint-Marc P, Seydoux J, et al. 2003. Arachidonic acid and prostacyclin signaling promote adipose tissue development: a human health concern? J Lipid Res 44(2): 271-279.

Massiera F, Barbry P, Guesnet P, et al. 2010. A Western-like fat diet is sufficient to induce a gradual enhancement in fat mass over generations. J Lipid Res 51(8): 2352-2361.

McManus S, Tejera N, Awwad K, et al. 2016. Differential effects of EPA versus DHA on postprandial vascular function and the plasma oxylipin profile in men. J Lipid Res 57(9): 1720-1727.

Moon RJ, Harvey NC, Robinson SM, et al. 2013. Maternal plasma polyunsaturated fatty acid status in late pregnancy is associated with offspring body composition in childhood. J Clin Endocrinol Metab 98(1): 299-307.

Muhlhausler BS, Ailhaud GP. 2013. Omega-6 polyunsaturated fatty acids and the early origins of obesity. Curr Opin Endocrinol Diabetes Obes 20(1): 56-61.

Negrel R, Gaillard D, Ailhaud G. 1989. Prostacyclin as a potent effector of adipose-cell differentiation. Biochem J 257(2): 399-405.

Okuno M, Kajiwara K, Imai S, et al. 1997. Perilla oil prevents the excessive growth of visceral adipose tissue in rats by downregulating adipocyte differentiation. J Nutr 127(9): 1752-1757.
Okuyama H, Ichikawa Y, Sun Y, Hamazaki T, Lands WE. 2007a. Cancers common in the USA are stimulated by omega 6 fatty acids and large amounts of animal fats, but suppressed by omega 3 fatty acids and cholesterol. World Rev Nutr Diet 96: 143-149.

Okuyama H, Ichikawa Y, Sun Y, Hamazaki T, Lands WE. 2007b. Mechanisms by which dietary fats affect coronary heart disease mortality. World Rev Nutr Diet 96: 119-141.

Ouellet V, Labbe SM, Blondin DP, et al. 2012. Brown adipose tissue oxidative metabolism contributes to energy expenditure during acute cold exposure in humans. J Clin Invest 122(2): 545-552.

Pahlavani M, Razafimanjato F, Ramalingam L, et al. 2017. Eicosapentaenoic acid regulates brown adipose tissue metabolism in high-fat-fed mice and in clonal brown adipocytes. $J$ Nutr Biochem 39: 101-109.

Perez-Chacon G, Astudillo AM, Balgoma D, Balboa MA, Balsinde J. 2009. Control of free arachidonic acid levels by phospholipases A2 and lysophospholipid acyltransferases. Biochim Biophys Acta 1791(12): 1103-1113.

Philp LK, Heilbronn LK, Janovska A, Wittert GA. 2015. Dietary enrichment with fish oil prevents high fat-induced metabolic dysfunction in skeletal muscle in mice. PLoS One 10(2): e0117494.

Pisani DF, Ghandour RA, Beranger GE, et al. 2014. The omega6-fatty acid, arachidonic acid, regulates the conversion of white to brite adipocyte through a prostaglandin/calcium mediated pathway. Mol Metab 3(9): 834-847.

Pisani DF, Amri EZ, Ailhaud G. 2015. Disequilibrium of polyunsaturated fatty acids status and its dual effect in modulating adipose tissue development and functions. Ocl 22(4): D405.

Pohl J, Woodside B, Luheshi GN. 2014. Leptin modulates the late fever response to LPS in diet-induced obese animals. Brain Behav Immun 42: 41-47.

Pouteau E, Aprikian O, Grenot C, et al. 2010. A low alpha-linolenic intake during early life increases adiposity in the adult guinea pig. Nutr Metab (Lond) 7: 8.

Riley CL, Dao C, Kenaston MA, et al. 2016. The complementary and divergent roles of uncoupling proteins 1 and 3 in thermoregulation. J Physiol 594(24): 7455-7464.

Romanovsky AA. 2005. Vioxx, Celebrex, Bextra.. do we have a new target for anti-inflammatory and antipyretic therapy? Am J Physiol Regul Integr Comp Physiol 288(5): R1098-R1099.

Rosenwald M, Wolfrum C. 2014. The origin and definition of brite versus white and classical brown adipocytes. Adipocyte 3(1): 4-9.

Rudolph MC, Young BE, Lemas DJ, et al. 2017. Early infant adipose deposition is positively associated with the n- 6 to n-3 fatty acid ratio in human milk independent of maternal BMI. Int $J$ Obes (Lond) 41(4): 510-517.

Sadeghi S, Wallace FA, Calder PC. 1999. Dietary lipids modify the cytokine response to bacterial lipopolysaccharide in mice. Immunology 96(3): 404-410.

Schmocker C, Zhang IW, Kiesler S, et al. 2018. Effect of Omega-3 fatty acid supplementation on oxylipins in a routine clinical setting. Int J Mol Sci 19(1).

Shen W, Wang C, Xia L, et al. 2014. Epigenetic modification of the leptin promoter in diet-induced obese mice and the effects of N-3 polyunsaturated fatty acids. Sci Rep 4: 5282.

Simopoulos AP. 2016. An Increase in the Omega-6/Omega-3 fatty acid ratio increases the risk for obesity. Nutrients 8(3): 128.

Simopoulos AP, DiNicolantonio JJ. 2016. The importance of a balanced omega- 6 to omega- 3 ratio in the prevention and management of obesity. Open Heart 3(2): e000385.

Smith GI, Atherton P, Reeds DN, et al. 2011. Omega-3 polyunsaturated fatty acids augment the muscle protein anabolic response to 
hyperinsulinaemia-hyperaminoacidaemia in healthy young and middle-aged men and women. Clin Sci (Lond) 121(6): 267-278.

Smith GI, Julliand S, Reeds DN, Sinacore DR, Klein S, Mittendorfer B. 2015. Fish oil-derived n-3 PUFA therapy increases muscle mass and function in healthy older adults. Am J Clin Nutr 102(1): $115-122$.

Stirban A, Nandrean S, Gotting C, Stratmann B, Tschoepe D. 2014. Effects of n-3 polyunsaturated fatty acids (PUFAs) on circulating adiponectin and leptin in subjects with type 2 diabetes mellitus. Horm Metab Res 46(7): 490-492.

Tachtsis B, Camera D, Lacham-Kaplan O. 2018. Potential roles of n-3 PUFAs during skeletal muscle growth and regeneration. Nutrients 10(3).

Tatro JB. 2000. Endogenous antipyretics. Clin Infect Dis 31 (Suppl. 5): S190-S201.

Ushikubi F, Segi E, Sugimoto Y, et al. 1998. Impaired febrile response in mice lacking the prostaglandin E receptor subtype EP3. Nature 395(6699): 281-284.
Vassaux G, Gaillard D, Ailhaud G, Negrel R. 1992. Prostacyclin is a specific effector of adipose cell differentiation. Its dual role as a cAMPand $\mathrm{Ca}(2+)$-elevating agent. J Biol Chem 267(16): 11092-11097.

Weber JM, Haman F. 2005. Fuel selection in shivering humans. Acta Physiol Scand 184(4): 319-329.

Weill P, Schmitt B, Chesneau G, Daniel N, Safraou F, Legrand P. 2002. Effects of introducing linseed in livestock diet on blood fatty acid composition of consumers of animal products. Ann Nutr Metab 46(5): 182-191.

Westerterp KR, Verboeket-van de Venne WP, Bouten CV, de Graaf C, van het Hof KH, Weststrate JA. 1996. Energy expenditure and physical activity in subjects consuming full-or reduced-fat products as part of their normal diet. Br J Nutr 76(6): 785-795.

Williams ES, Baylin A, Campos H. 2007. Adipose tissue arachidonic acid and the metabolic syndrome in Costa Rican adults. Clin Nutr 26(4): 474-482.

Zhang F, Hao G, Shao M, et al. 2018. An adipose tissue atlas: an image-guided identification of human-like BAT and beige depots in rodents. Cell Metab 27(1): 252-262 (e253).

Cite this article as: Pisani DF, Ailhaud G. 2019. Involvement of polyunsaturated fatty acids in the control of energy storage and expenditure. OCL 26: 37 . 